\title{
El Señor del Perdón y los matacristos de Oaxaca: la Revolución Mexicana desde el punto de vista de los católicos*
}

\author{
Benjamin Smith
}

Este artículo examina las respuestas religiosas a una década de violencia producto de la Revolución Mexicana que estalló en 1910, en dos comunidades del estado de Oaxaca —San Pablo y San Pedro Tequixtepec, en la Mixteca Baja,y en Magdalena Tequisistlán, en el Istmo de Tehuantepec-. En Tequixtepec el diálogo entre el clérigo y el sector laico propició una innovación ortodoxa, aceptada por las autoridades eclesiásticas. En Tequisistlán, la falta de negociación religiosa causó un renacimiento religioso menos aceptable: la crucifixión de un viajero italiano.

PaLABRAS CLAVE: Oaxaca, cultura religiosa, violencia, resistencia, cultos milenaristas

The Lord of Pardon (Señor del Perdón) and the Matacristos of Oaxaca: the Mexican Revolution from the Catholics' Point of View

This article explores the religious responses to the violence of the Mexican Revolution in two communities in the state of Oaxaca - San Pablo y San Pedro Tequixtepec in the Mixteca Baja and Magdalena Tequisistlan in the Isthmus of Tehuantepec. In Tequixtepec the dialogue between the clergy and the lay worshippers precipitated an orthodox innovative, accepted by the ecclesiastical authorities. In Tequisistlan, the lack of religious negotiations caused a less acceptable religious revival, the crucification of an Italian traveller.

KEYWORDS: Oaxaca, religious culture, violence, resistance, Millenarist worship

\author{
BENJAMIN SMITH: Michigan State University, Estados Unidos \\ bensmith@msu.edu \\ Traducción: Noemí Morales Sánchez
}

Desacatos, núm. 34, septiembre-diciembre 2010, pp. 61-76

Recepción: 31 de agosto de 2009 / Aceptación: 12 de marzo de 2010

\footnotetext{
* Quiero agradecer especialmente a Ricardo Ceballos Soto, al padre Gregorio Eduardo Rivera, a Serafín Sánchez, a John Wisti y a Noemí Morales Sánchez, quienes me ayudaron en la preparación de este artículo.
} 
$\mathrm{L}$

a Revolución Mexicana fue un movimiento popular y agrario que redistribuyó entre los campesinos del país las tierras comunales privatizadas. Sin embargo, muchos campesinos no experimentaron esa década de violencia, enfermedades y escasez como un evento libertador o positivo ${ }^{1}$. Como afirmó Luis González y González hace 30 años, fuera de las regiones de reciente capitalización y con tensiones entre las clases sociales, a menudo los campesinos experimentaron el periodo como uno de "crímenes salvajes, atracos, secuestros, cuerpos ahorcados, mujeres violadas e imágenes religiosas quitadas de sus milagros". Los campesinos no fueron pasivos ni "no revolucionarios", sino activa y violentamente "revolucionados" (González y González, 1985; Waterbury, 1975). Además, según los historiadores, el ritmo agitado de la vida cotidiana con frecuencia los forzó a revisar las relaciones con sus santos patronos, a los que habían venerado para evitar este tipo de trastornos violentos (Wright-Rios, 2009). En todo México, los curas y los fieles crearon y recrearon la iconografía, los rituales y las creencias locales y religiosas para amenazador.

Este artículo examina dos intentos de regresar a un pasado imaginario de orden, estabilidad y abundancia: uno en el pueblo mixteco San Pablo y San Pedro Tequixtepec, en 1919, y el otro en el pueblo chontal Magdalena Tequisistlán, en el Istmo de Tehuantepec, en 1920. En ambas comunidades, unos cuantos vecinos se unieron a la Revolución. Otros vivieron la década como un decenio de hambre, sangre y epidemias. Además, las dos poblaciones percibieron su sufrimiento como retribución divina. Sin embargo, mientras en Tequixtepec el diálogo entre la Iglesia y el sector laico provocó una innovación casi ortodoxa, en Tequisistlán la Iglesia no pudo hacer uso de la religiosidad indígena y se produjo un escandaloso cambio espiritual nada ortodoxo.

\footnotetext{
${ }^{1}$ Véase, por ejemplo, Knight, 1986.
}

\section{SAN PABLOY SAN PEDRO TEQUIXTEPEC Y EL SEÑOR DEL PERDÓN}

Tequixtepec está en el centro de la Mixteca Baja, una región seca, montañosa y erosionada en la frontera entre los estados de Oaxaca, Guerrero y Puebla. Aunque esta zona fue importante en el camino real, no hubo mucha inmigración mestiza o española fuera de la ciudad de Huajuapan de León. En 1849, el cura de Tequixtepec identificó a sus fieles como "mixtecos". A pesar de que las escuelas eclesiásticas aumentaron las competencias lingüísticas en español y ocasionaron un descenso en el monolingüismo indígena, el pueblo no sufrió una intromisión externa significativa ${ }^{2}$. Durante el Porfiriato, el terreno de la Mixteca Baja era demasiado pobre para atraer a la naciente burguesía rural (Smith, 2009: 225-226), y en 1906 la población del pueblo de Tequixtepec era de 1000 habitantes, de los cuales casi $90 \%$ hablaba español y solamente $10 \%$ mixteco $^{3}$. La mayoría de los pobladores vivía de la agricultura, el tejido de palma o la pastura de ganado menor y mayor.

Cuando estalló la Revolución en 1910, la distribución de la tierra en la Mixteca Baja era relativamente equitativa. Había un pequeño número de fincas de azúcar en los alrededores de Huajuapan de León y otras cuantas en La Pradera, donde había también grandes plantaciones. Sin embargo, muchos campesinos poseían las tierras como parte de las sociedades agrícolas, un tipo de condueñazgo establecido a raíz de las leyes de desamortización con el objetivo de comprar tierras de caciques indígenas y mantenerlas entre los vecinos de cada comunidad (Smith, 2009: 226; Monaghan, 2002). En consecuencia, aunque algunos rancheros mestizos se armaron en 1910, más que reforma social buscaban poder político, y carecían de apoyo popular (Reyes Aguilar, 1972: 31). En general, la Revolución arribó a la Mixteca Baja de la mano de grupos zapatistas itinerantes que vinieron de las fincas azucareras del norte y del oeste. Si bien estos grupos con frecuencia actuaban como bandidos sociales en sus re-

\footnotetext{
2 Archivo de la Parroquia de Huajuapan de León, Padrones, 1849; Dirección General de Estadísticas, 1906.

${ }^{3}$ Idem.
} 


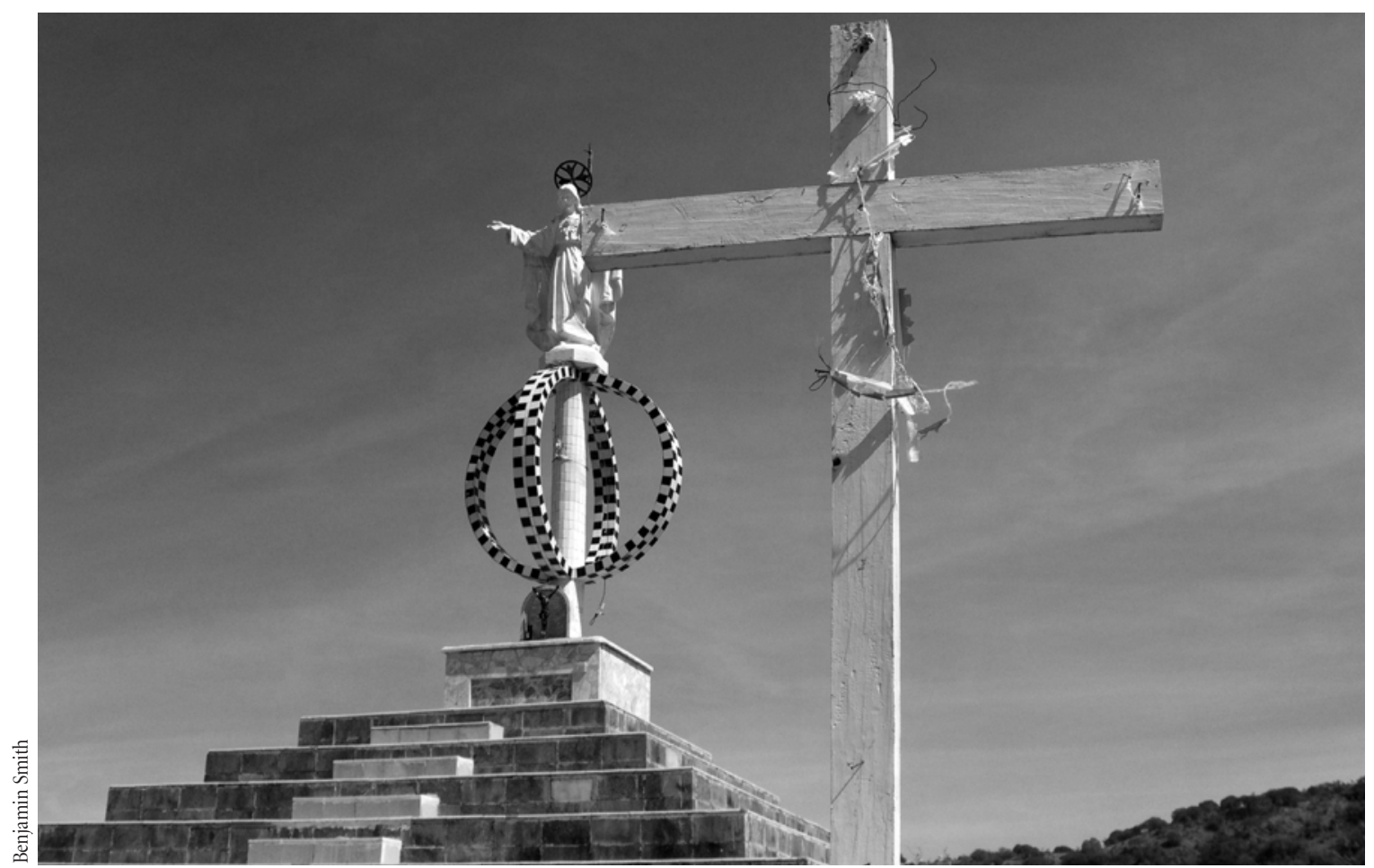

El monumento al Cristo Rey afuera de San Pablo y San Pedro Tequixtepec, 2008.

giones de origen, que estaban bajo su influencia, invadiendo fincas de terratenientes impopulares, distribuyendo comida y evitando conflictos en las comunidades de los campesinos, fuera de ese ámbito se asemejaban más a los ladrones sicilianos descritos por Anton Blok (Hobsbawm, 1959; Blok, 1972; Brunk, 1996).

Por ejemplo, el 6 de febrero de 1913, el zapatista Miguel Mendiola sitió Tequixtepec y demandó la cantidad de 5000 pesos, con la amenaza de quemar el pueblo y matar a la gente si no se le entregaba el dinero. Las autoridades visitaron las casas, fingiendo que recogían el dinero, pero en realidad organizaban un ataque contra los revolucionarios. Al mediodía, los vecinos atacaron el palacio municipal, donde estaban los zapatistas, mataron a su líder y forzaron a los demás a retirarse ${ }^{4}$. Un año después, el grupo regresó para vengarse. Otra vez el pueblo

\footnotetext{
${ }^{4}$ Archivo del Municipio de Tequixtepec, Presidencia 1913, Autoridades Municipales a Presidente Huerta, 7 de febrero de 1913.
}

se resistió e hizo prisionero a su cabecilla, Rafael Navarrete. Con todo y que su esposa imploró su perdón, las autoridades de Tequixtepec lo enviaron a Huajuapan de León, donde fue ejecutado ${ }^{5}$. Finalmente, el 17 de mayo de 1914, los zapatistas, bajo el mando del revolucionario guerrerense Mucio Bravo, tomaron el pueblo. Trescientos hombres atacaron y quemaron todas las casas, forzando a los habitantes a refugiarse en los cerros. Robaron el maíz, el ganado y los ornamentos de la iglesia ${ }^{6}$. En agosto, cuando llegó el nuevo cura, no encontró "nada excepto ruinas, montañas de cenizas, y árboles quemados y desolación sin ninguna clase de animales"7. Después del ataque, los vecinos de Tequixtepec se quedaron seis meses en

\footnotetext{
${ }^{5}$ Anacleto Vivas, "Incineración de Tequixtepec", Memoria particular; Archivo de la Parroquia de Tequixtepec (APT), Libros de Gobierno, 3 de mayo de 1914.

${ }^{6}$ Luis Niño, "Apuntes Históricos de Tequixtepec", Memoria particular; APT, Libros de Gobierno, 17 de mayo de 1914.

${ }^{7}$ APT, Libros de Gobierno, 1 de agosto de 1914.
} 
jacales en los cerros, y regresaron lentamente al pueblo. Durante los siguientes cinco años, sufrieron hambre (1915), tifoidea (1916) e influenza española. Aunque no se cuenta con la documentación en Tequixtepec, la enfermedad mató a cientos de parroquianos en el cercano pueblo de Tezoatlán- ${ }^{8}$.

Los curas y los laicos vieron las invasiones, robos y defensas, con y sin éxito, como guiados por el favor de Dios, como si los trastornos de la Revolución hubieran aumentado su sentido de la providencia divina. Por ejemplo, cuando los vecinos del pueblo vencieron a los zapatistas el 3 de mayo 1914, el cura anunció que fue "un milagro postulado por Dios y María Santísima del Perpetuo Socorro, que protegió al pueblo en su hora de peligro"9. Cuando los zapatistas atacaron el pueblo colindante de Santa Gertrudis y fueron vencidos en diciembre de 1913, el cura afirmó que fue "un milagro del Santísimo" 10 . Aun cuando los revolucionarios quemaron el pueblo, el mismo cura argumentó que la única casa que sobrevivió era debido a "la vida práctica cristiana" del dueño ${ }^{11}$. Los pobladores compartieron este sentido de continua intervendijo al padre que escapó de las balas de los zapatistas por la intervención de la Virgen del Perpetuo Socorro y la Santa Cruz. Veinte años después escribió que sintió como si lo hubiera movido "una fuerza supernatural"12.

Los católicos de Tequixtepec creyeron que la sobrevivencia del pueblo dependía de la intervención divina y buscaron la manera correcta de persuadir a Dios para que intercediera por ellos. En 1913 parecía que la devoción al Santísimo Sacramento había funcionado. El padre se postró ante la sagrada hostia durante la derrota zapatista y todas las fieles hicieron lo mismo durante la batalla de Santa Gertrudis ${ }^{13}$. También se dirigieron a la iglesia diocesana de la Virgen de Guadalupe en Huajuapan de

\footnotetext{
${ }^{8}$ Archivo de la Parroquia de Tezoatlán, Libros de Gobierno, 2 de noviembre de 1919.

${ }^{9}$ APT, Libros de Gobierno, 3 de mayo de 1914.

10 APT, Libros de Gobierno, 1 de enero de 1914.

${ }^{11}$ APT, Libros de Gobierno, 17 de mayo de 1914.

${ }^{12}$ Luis Niño "Apuntes Históricos de Tequixtepec", manuscrito.

${ }^{13}$ APT, Libros de Gobierno, 16 de febrero de 1913; APT, Libros de Gobierno, 1 de enero de 1914.
}

León y a la patrona de Chinango, Santa Catalina, y organizaron peregrinaciones muy concurridas ${ }^{14}$. En 1914, los vecinos del pueblo empezaron a adorar a la Virgen del Perpetuo Socorro. Al parecer, esta advocación también funcionó y ayudó a la derrota de los revolucionarios el 3 de mayo y a la escapatoria de Luis Niño Pacheco semanas después. Por eso compraron una imagen ${ }^{15}$. Pero la virgen empezó a perder su eficacia cuando la hambruna y las epidemias golpearon fuertemente al pueblo durante los últimos años de la década.

En 1919, los vecinos de Tequixtepec estaban desesperados y los sufrimientos continuaban a pesar de las sugerencias del cura. En consecuencia, trataron de construir su propia solución con las materias primas del catolicismo local. Según las leyendas de la región, una mujer, probablemente Virginia Perpetua viuda de Hernández, líder de las Hijas de María, tuvo una visión. Afirmó que si clavaban al Santo Entierro en una cruz, lo ponían en el altar central de la iglesia e imploraban el perdón por sus pecados, Dios terminaría con el sufrimiento del pueblo. Lo llamarían el Señor del Perdón ${ }^{16}$. Debido a que el nuevo culto estaba basado en tradiciones establecidas por la parroquia y abrazaba un nuevo espíritu de arrepentimiento y misericordia, la jerarquía eclesiástica lo aceptó rápidamente. En 1919, durante la segunda semana de Cuaresma, el padre Daniel Salazar acordó institucionalizar una celebración para el nuevo santo del pueblo y desfiló con la imagen "con el esplendor más grande"17. Como los estragos de la guerra cedieron, la nueva ceremonia se volvió cada vez más popular y muchos le atribuyeron el fin de la violencia revolucionaria. En 1921, el clero local acordó bendecir la nueva imagen, organizó una misa de tres curas y nombró a los padrinos para la ceremonia de la bendición. Los creyentes llegaron de los pueblos colindantes, hubo fuegos artificiales, música con tres bandas y, según Salazar, "mucha piedad fue testigo de ella"18. En el último siglo, la reputación de la imagen

\footnotetext{
${ }^{14}$ APT, Libros de Gobierno, 12 de marzo de 1913; APT, Libros de Gobierno, 30 de abril de 1914 .

15 APT, Libros de Gobierno, 17 de mayo de 1914.

${ }^{16}$ Entrevista con Gregorio Eduardo Rivera, marzo de 2008.

${ }^{17}$ APT, Libros de Gobierno, 14 de marzo de 1919.

18 APT, Libros de Gobierno, 19 de febrero de 1921.
} 
aumentó. Miles de peregrinos asisten a la ceremonia cada año, desde distintos puntos, como el Distrito Federal, Puebla y los Estados Unidos.

\section{LA CULTURA RELIGIOSA LOCAL}

La fundación y la aceptación del culto del Señor del Perdón tal vez parezcan sencillas —una de las muchas leyendas pueblerinas de renovación religiosa- Pero el proceso de cambiar al santo patrono no fue fácil. Según Edward Wright-Rios, la iglesia del Porfiriato era extremadamente cautelosa ante las innovaciones laicas. Unos años antes, el arzobispo de Oaxaca, Eulogio Gillow, trató de reprimir un culto similar al Cristo en el valle de Tehuacán, a menos de $50 \mathrm{~km}$ de distancia de Tequixtepec (Wright-Rios, 2009: 164-205). El surgimiento del culto del Señor del Perdón revela un entendimiento profundo, y una simpatía, entre los curas y el sector laico en Tequixtepec, producto de décadas de intensos diálogos sobre obligaciones mutuas y ortodoxia eclesiástica. Normalmente, esta negociación cotidiana entre el clero y los laicos es un poco oscura y la percibimos sólo en la interacción entre las partes por medio de las cartas de quejas, frustración y desacuerdos, o informes judiciales contradictorios. Como argumenta William Taylor, durante el siglo XVIII, en muchas regiones el diálogo discreto y desordenado, las tensiones y la heterodoxia fueron usuales (Taylor, 1996: 7). Afortunadamente, en $1890 \mathrm{el}$ obispo de Puebla pidió que los curas locales guardaran un diario de la vida litúrgica y las relaciones entre la Iglesia y el pueblo. Estos “Libros de Gobierno” han quedado para Tequixtepec y explican por qué los vecinos del pueblo establecieron el culto al Señor del Perdón y por qué la iglesia lo aceptó sin problema.

Durante los últimos años del siglo XIX, la jerarquía eclesiástica de México empezó a crear una serie de pequeñas y dinámicas diócesis, atendidas por curas nacidos en el lugar (O'Dogherty, 1998; Sánchez R., 1992; Hernández Madrid, 1994). Los obispos de estas nuevas diócesis indujeron el resurgimiento de la Iglesia católica con una mezcla de reforma clerical, catolicismo social y tradición regional (Guerra, 1985: 199-206; Alcalá Alvarado, 1984;
Gutiérrez Casillas, 1974: 326-357; Brading, 2001: 289290). Unos tuvieron más éxito que otros. El obispado de Tehuantepec, establecido en 1891, fracasó. Sin embargo, por múltiples causas, el obispado de la Mixteca (llamado de Huajuapa de León en 1904) tuvo un éxito relativo. La jerarquía fue lo suficientemente inteligente como para designar a Rafael Amador y Hernández como el primer obispo de esa diócesis. Hijo de un mestizo pobre del pueblo de Chila, Amador recibió una beca del cura local para estudiar en la escuela católica de Puebla. Las autoridades eclesiásticas percibieron su inteligencia y lo enviaron al Colegio Pío Latino en Roma para prepararse como sacerdote. Al regresar a México, ascendió rápidamente en la jerarquía eclesiástica. En 1891 fue vicario foráneo de Huajuapan de León ${ }^{19}$. Si bien Amador mantuvo contacto con prelados conservadores como Plancarte y Gillow, también fue sensible a los cambios, al diálogo y los compromisos necesarios para el éxito de la Iglesia en una región indígena. Mientras Gillow comparó la heterogeneidad lingüística de Oaxaca con la de Babel, Amador animó a sus curas a que aprendieran a hablar y a confesar en mixteco. Al mismo tiempo, abarcó los lugares sagrados locales, como el santuario de la Virgen de las Nieves en Ixpantepec ${ }^{20}$. Aunque Amador esperaba deferencia y obediencia a cambio de su indulgencia, fue suficientemente flexible para hacer funcionar este sistema paternalista.

Al inicio del siglo XX, el seminario empezó a formar sacerdotes locales imbuidos por la visión paternalista de Amador, a quienes llevaron a las parroquias de la nueva diócesis. En conjunto, institucionalizaron múltiples innovaciones en constante diálogo con los fieles, e incluso impulsaron escuelas católicas, grupos laicos, organizaciones de caridad, hospitales y nuevas cofradías. Pero en Tequixtepec influyeron particularmente tres elementos en la eventual creación del Señor del Perdón: primero,

\footnotetext{
${ }^{19}$ Valverde Téllez, 1949: 103-107; Cantú Corro, s. f.; Archivo de la Diócesis de Huajuapan de León (ADH), Carpetas "Historia de Huajuapan”, "Biografía del Ilmo. Y Rvdmo. Sr. Dr. D. Rafael Amador y Hernández".

${ }^{20}$ ADH, Circular 17, 7 de julio de 1909; ADH, Obispo Amador a Porfirio López, 2 de enero de 1912; ADH, Parroquias, Silacayoapam, Informe, 19 de marzo de 1917.
} 


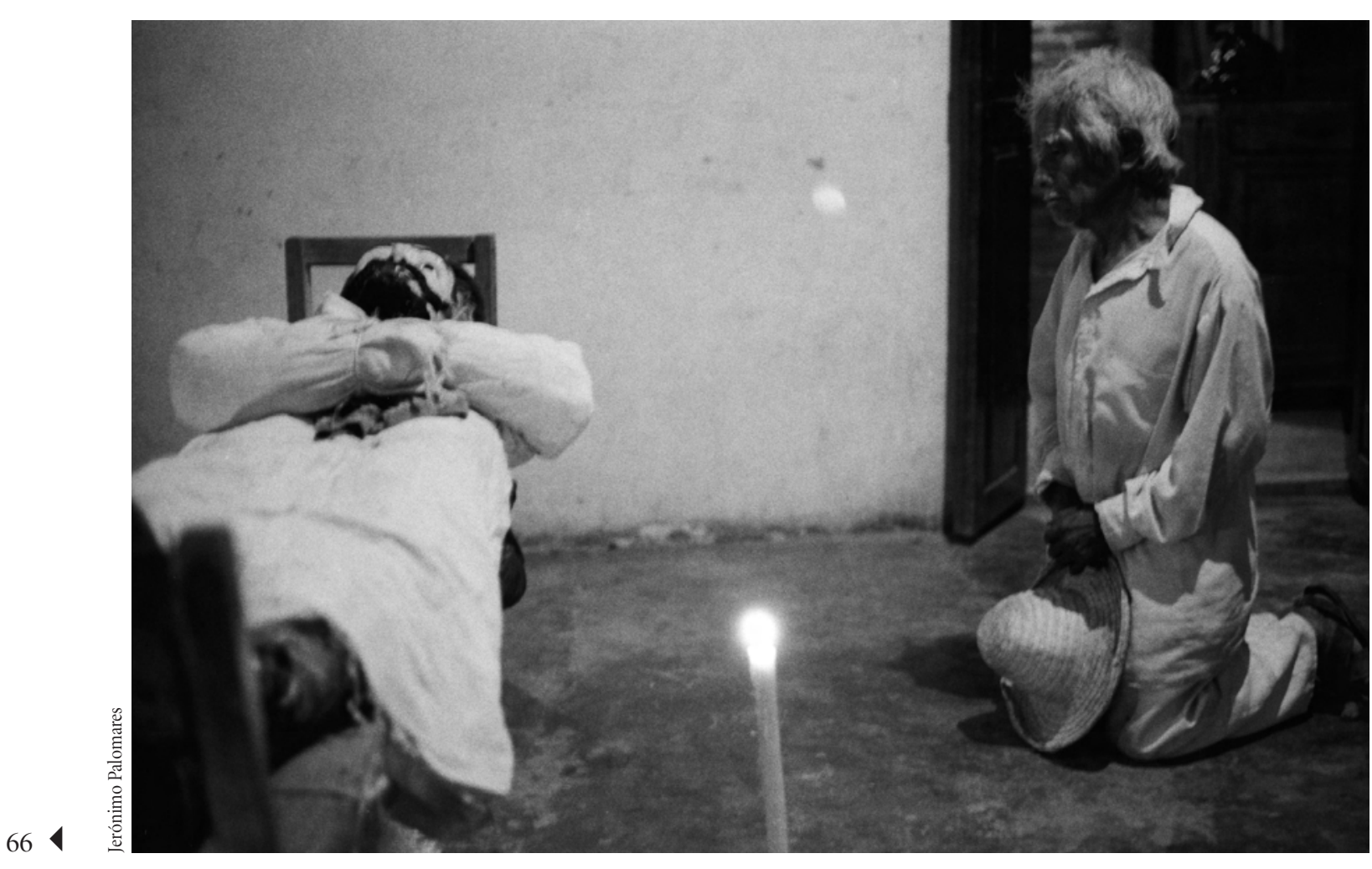

Semana Santa en Venustiano Carranza, Chiapas, 2005.

los nuevos curas formalizaron el papel central de las mujeres en la Iglesia; segundo, animaron las innovaciones laicas al autorizar una serie de cultos que anteriormente se mantenían en casas particulares o en lugares aislados, y tercero, como consecuencia de lo anterior, inspiraron la confesión regular y la contrición —el sanctum sanctorum del trabajo pastoral desde la época colonial-.

Las mujeres siempre desempeñaron un papel importante en las fiestas de los pueblos, pero durante los últimos años del siglo XIX la Iglesia católica las puso a la vanguardia del renacimiento religioso y de la defensa ante el secularismo, lo que Edward Wright-Rios llama "una piedad femenina sobrealimentada" (Monaghan, 1995: 165; Wright-Rios, 2006: 184). A lo largo y ancho de México, los prelados y los curas animaban la creación de organizaciones laicas de mujeres piadosas y las involucraban en la vida cotidiana de la parroquia. En 1910, José Cantú Corro, graduado del seminario diocesano, estableció la rama de las Hijas de María Inmaculada en Tequixtepec. En un principio, el grupo estaba formado por 12 miembros especialmente escogidos, pero en cuatro años creció a 50. Las mujeres se reunían los jueves, los domingos y los días festivos para discutir la doctrina de la Iglesia y la organización de las fiestas, y para asignar los deberes específicos en la parroquia. Además, cada 19 de diciembre celebraban el día de la Purísima Concepción de María y pagaban por misas durante todo el mes de mayo en honor a la Madre de Dios. La pertenencia a la asociación tenía un peso social muy fuerte que Cantú Corro alentaba. Estableció que las afiliadas fueran vestidas con faldas blancas durante los días festivos y constituyó un grupo permanente de aspirantes, marcado por sus cinturones verdes. El clérigo también creó un grupo activo de celadoras jóvenes, encargadas de la enseñanza del catecismo a los niños del pueblo. Ellas organizaban concursos de entendimiento y memorización al mismo tiempo que 
exhortaban a los padres a permitir la asistencia de los niños ${ }^{21}$. Según Cantú Corro, las celadoras de Yolotepec persuadieron a 50 niños, quienes cada domingo caminaban $8 \mathrm{~km}$ a Tequixtepec para recibir instrucción religio$\mathrm{sa}^{22}$. Finalmente, los curas de Tequixtepec otorgaron a las mujeres la responsabilidad de las finanzas para las actividades de la parroquia, un papel que desempeñaban los hombres de la Sociedad Católica. Por ejemplo, en diciembre de 1911 Cantú Corro autorizó a la señora Antonia Reyes viuda de Cumplido a recoger limosnas para comprar la imagen de María Santísima del Carmen, argumentando que ella era "tan piadosa que a pesar de ser completamente pobre" podía recoger todo el dinero que era necesario ${ }^{23}$.

De hecho, durante estos años los curas daban la impresión de que las mujeres dominaban en la iglesia local, como devotas administradoras y como madres de los niños —el futuro de la Iglesia—. Además, creían que su piedad iba a traer la salvación al México de la Revolución. En 1911 la diócesis ordenó que los sacerdotes fueran devotos durante todo el mes de mayo debido a la primera comunión de los niños y a los rezos para la paz en México bajo los auspicios de la virgen. En Tequixtepec, las mujeres piadosas organizaron todos los eventos. Las celadoras prepararon un mes de clases de catecismo, buscando y animando a los niños. Esto culminó en una primera comunión para más de 100 niños de la parroquia, acompañados por mujeres jóvenes y 30 madrinas. Los seguían las Hijas de María, "con vestido y velo de blanco" 24 .

Mientras los curas de Tequixtepec creaban una élite religiosa femenina, que eventualmente erigiría al Señor del Perdón, también institucionalizaban la innovación litúrgica. Por una parte, concedieron la aprobación oficial a las devociones locales y particulares, con lo que se animó el entusiasmo devocional. Por ejemplo, la cofradía del santo patrón de Santa Gertrudis quiso celebrar un culto a Cristo durante la Semana Santa. El cura permitió la innovación y bendijo el Santo Entierro en 1912. El pue-

${ }^{21}$ APT, Libros de Gobierno, 30 de junio de 1910.

22 APT, Libros de Gobierno, 29 de marzo de 1911.

${ }^{23}$ APT, Libros de Gobierno, 26 de julio de 1911.

${ }^{24}$ APT, Libros de Gobierno, mayo de 1910. blo entero asistió a la ceremonia ${ }^{25}$. Por otra parte, oficializaron la práctica de cambiar el nombre, la posición y el significado de los cultos existentes. En 1892, el cura Antonio Cisneros autorizó a los vecinos de Tequixtepec a convertir la imagen del Señor del Desmayo en la del Señor de los Santos Lugares de Jerusalén. Los diezmos que recogieron fueron enviados al cura de Cholula - en lugar de al arzobispado de Puebla-, quien los envió a Jerusalén ${ }^{26}$. En 1914, en la cuarta semana después de la Semana Santa, el cura asistió a la solemne celebración tradicional del Cristo. El nombre de la imagen del Señor Santuario fue cambiado por el de Señor de Clemencia, según cabe suponer para enfatizar sus atributos de perdón ${ }^{27}$. Al permitir estos cambios litúrgicos, las autoridades eclesiásticas institucionalizaron un proceso de diálogo que hizo posible la aceptación del culto al Señor del Perdón.

Finalmente, los curas locales usaron su creciente influencia para animar a la gente a confesarse con frecuencia y, al menos en su opinión, de manera significativa. El ritual vinculó el destino de México, la diócesis y el pueblo a un particular sentido de pecado. En Europa, los historiadores han impugnado la evaluación y la sugerencia de un sentido ortodoxo del pecado, de la contrición y del perdón. En América Latina, la escasa investigación existente indica que fue la parte más difícil de la evangelización y de su aceptación. Aun el clero optimista del periodo colonial se desilusionó ante la incapacidad de los indígenas de aceptar esta creencia (Taylor, 1996: 224226). Sin embargo, los Libros de Gobierno sugieren una enseñanza prudente, combinada con la amenaza de la violencia revolucionaria, que lentamente persuadió a los vecinos del pueblo a conectar su propio sentido de pecado, entendido desde el punto de vista católico a través de la institución de la confesión, con eventos del mundo real. En uno de los pasajes más interesantes de los libros, Cantú Corro explicó su técnica. Durante la segunda semana de Cuaresma de 1911 visitó el pueblo de Santa Gertrudis. El año anterior, el cura y su vicario, José López

\footnotetext{
${ }^{25}$ APT, Libros de Gobierno, 29 de marzo de 1911.

${ }^{26}$ APT, Libros de Gobierno, Visita parroquial, 1892.

${ }^{27}$ APT, Libros de Gobierno, 8 de mayo de 1914.
} 
Vásquez, habían empezado "un cuestionario más o menos lato y otros pensamientos dichos en mixteco" para confesar a los fieles indígenas y monolingües. Contribuyó al cumplimiento de esta tarea la "afabilidad en el teatro social y su dulzura paternal en el confesionario" de López Vásquez. Manifestó que en la Cuaresma "la gente pobre" había "perdido su temor y asistieron a los sacramentos". Estimó que en este periodo había confesado a más de 1500 fieles o casi a 80\% de la población de la parroquia ${ }^{28}$. $\mathrm{Al}$ año siguiente, cuando el obispo visitó el pueblo, comentó que hubo un "aumento obvio de piedad", una mayor frecuencia de sacramentos, y un fervor "despertado en los fieles por el cura" ${ }^{\text {". }}$. Este cambio en el entendimiento de la importancia de una moralidad personal y cristiana tal vez alentó la desaparición de matrimonios informales y la conformación de matrimonios eclesiásticos. Con frecuencia, Cantú Corro hizo alarde de la formalización de las "uniones escandalosas" en la parroquia. En 1913, anunció que solamente una pareja vivía en pecado "porque el hombre estaba trabajando en Veracruz" ${ }^{30}$. En general, esta economía providencial de pecado, contrición, perdón y redención dio la impresión de parar la creciente miseria de la Revolución.

En conjunto, los cambios producidos durante estos años de diálogo canalizaron la piedad laica hasta sistemas aceptables de entusiasmo cristiano. Por consiguiente, la Iglesia aceptó estas innovaciones laicas. Además, el proceso vigorizó el catolicismo local, que al mismo tiempo sufría mayores presiones del anticlericalismo revolucionario. En muchas regiones, los catolicismos indígenas se hundieron y los adoradores abrazaron los beneficios económicos y educacionales de su colusión con el gobierno; salvo los rituales esenciales, abandonaron todos y regresaron a sus santuarios no autorizados. Pero en Tequixtepec y en los otros pueblos de la Mixteca Baja los curas y los fieles mantuvieron un frente unido contra el Estado posrevolucionario, lucharon en la Cristiada, rechazando las escuelas estatales, y eventual-

\footnotetext{
${ }^{28}$ APT, Libros de Gobierno, 29 de marzo de 1911. En este momento la parroquia también incluyó unos pueblos colindantes.

${ }^{29}$ APT, Libros de Gobierno, 17 de julio de 1912.

${ }^{30} \mathrm{APT}$, Libros de Gobierno, 30 de junio de 1910.
}

mente apoyaron al Partido Acción Nacional (PAN) (Smith, 2007: 261-278).

\section{LOS “MATACRISTOS” DE MAGDALENA TEQUISISTLÁN}

Magdalena Tequisistlán es un pueblo chontal al oeste del Istmo de Tehuantepec. Aunque la construcción de redes de ferrocarriles, la industrialización y la capitalización agrícola precipitaron tensiones sociales muy serias en la región, Tequisistlán fue afectado en menor medida (Chassen-López, 2005: 60-68, 111-127). Los chontales habían perdido la mayoría de sus terrenos en favor de los españoles y los zapotecos antes del siglo XIX. Por consiguiente, pocos hacendados ambicionaron las tierras de Tequisistlán durante el boom del Porfiriato. Para 1900, los vecinos del pueblo sobrevivían gracias a cultivos básicos como maíz y frijol y a la carne de sus rebaños de ganado mayor ${ }^{31}$. Además, aunque unos mineros habían empezado a investigar los depósitos de mármol alrededor del pueblo, no iniciaron enseguida la extracción y, cuando lo hicieron, emplearon la mano de obra del lugar (Al-Shimas, 1922: 192-193). Según el historiador local Leonardo Ramírez Díaz, "los ciudadanos de Magdalena Tequisistlán no participaron directamente en el movimiento armado". La mayoría continuó "dedicándose a sus labores en el campo". Los campesinos de Tequisistlán, como los de Tequixtepec, recuerdan el periodo como una época de bandolerismo, pobreza y "tristeza profunda” (Ramírez Díaz, 2005). Como los mixtecos del norte, intentaron resucitar la fortuna del pueblo con la adaptación de rituales tradicionales y católicos.

A las tres de la tarde del 2 de abril de 1920, los vecinos del pueblo empezaron su procesión tradicional del Viernes Santo en la parroquia, para llegar a la cumbre del Cerro del Calvario. Al frente de la procesión iba un italiano, José di Gabrielli, vestido con "unos calzoncillos de paños y una corona de espinas", cargando una cruz gigante. Las mujeres lloraban y los niños vestidos de blanco cantaban himnos religiosos. Cuando llegaron a la cima, cuatro

${ }^{31}$ Dirección General de Estadísticas, 1906. 
hombres tendieron a Di Gabrielli y clavaron sus pies y sus manos a la cruz. A pesar del dolor, no se quejó. Los vecinos levantaron lentamente la cruz. Di Gabrielli entró en un tipo de trance, balbuceando unas cuantas palabras incomprensibles. Después de unas horas gritó y pidió que lo bajaran. Los vecinos, también lentamente, bajaron el crucifijo, quitaron los clavos y pusieron al italiano en una mesa al lado de la cruz. Durante la noche, cuidaron sus heridas, temiendo que el extranjero muriera. Eventualmente, el juez local ordenó que el pueblo entregara al italiano y a los involucrados en su crucifixión a la cabecera del distrito, Tehuantepec. Los vecinos pusieron al italiano herido en una carreta y lo llevaron a la ciudad, mientras rezaban y quemaban incienso. Aunque el juez inició un procedimiento criminal contra campesinos, a quienes llamó "los matacristos de Tequisistlán", no lo completó por petición de Di Gabrielli, y los dejó en libertad ${ }^{32}$.

La historia de la crucifixión de Di Gabrielli se ha escrito en periódicos, revistas y autobiografías. La mayoría de los textos trata el acontecimiento como una farsa divertida y extraordinaria, un interesante pero incompresible entreacto en el drama de la Revolución. Números contemporáneos de El Universal y Excélsior describen la crucifixión como algo raro y "extraño", "sin precedentes" e "increíble"33. Un artículo en Letras, publicado en 1934, describe los hechos como "extraordinarios" 34 . Ignacio Muñoz, en su historia de la Revolución (cuatro volúmenes), soslaya el conocimiento básico e histórico y señala que la crucifixión solamente ocurrió "dos veces en la historia de la humanidad” (Muñoz, 1960: 173). Pero a pesar de la singularidad del evento, en general, los autores ofrecen tres explicaciones: la angustia psicológica individual, el fanatismo religioso y la mentalidad "provincial" de los indígenas chontales. El artículo en Letras y otro publica-

\footnotetext{
32 Las fuentes para esta narrativa son Excélsior, 5 de abril de 1920; El Universal, 5 de abril de 1920; Singer, 1998; Archivo Particular de Raúl Urquidi (APRU), Testamento de José di Gabrielli, Documentos judiciales de José di Gabrielli; Bustillo Bernal, 1968: 135-137; Muñoz, 1960, vol. 2: 173-187; Letras, abril de 1934; Ochoa Hernández, 1987.

${ }^{33}$ El Universal, 5 de abril de 1920; Excélsior, 5 de abril de 1920; Excélsior, 13 de abril de 1922.

${ }^{34}$ Letras, abril de 1934.
}

do en la revista médica estadounidense The Urologic and Cutaneous Review usan el caso para examinar la patología de la demencia. En The Urologic and Cutaneous Review un médico prueba a partir de este hecho la afirmación de Havelock Ellis de que el dolor inflingido a uno mismo, inspirado por la religión, está ligado a la excitación sexual ${ }^{35}$. Las versiones anticlericales mexicanas narran la historia para demostrar el extremismo del catolicismo europeo y describen al italiano como un "loco", "demente" y "extraviado"36. Por último, todas las explicaciones enfatizan el aislamiento, la indigenidad y la credulidad de los seguidores de Di Gabrielli. En 1922 un artículo en el Excélsior describe a Tequisistlán como "perdido en las sinuosidades de la sierra oaxaqueña". Se escribió que los devotos eran "indios humildes", "pobres" y "labriegos humildes"37.

Estas versiones son reveladoras, pero al moldear la historia para encajarla en las preocupaciones contemporáneas sobre la sexualidad, el fanatismo religioso y la exclusión indígena burlaron, subvaloraron y desecharon el entusiasmo del mesías italiano y sus seguidores chontales. Sabemos poco de José di Gabrielli. Según el informe judicial, nació en Sicilia, Italia, pero trabajó como médico en Pachuquilla, Hidalgo, desde la década de 1900. Di Gabrielli dijo que regresó a Europa en 1918 pero, encontrando el continente en medio de la guerra, volvió a México creyendo que era "Jesús de Nazaret, Dios del Cielo y de la Tierra"; que tuvo conversaciones con Dios y que su muerte redimiría a la humanidad por segunda vez. Para un experto en la religiosidad moderna italiana, los documentos tal vez revelan un Menocchio moderno, quien mezcló rumor, ortodoxia, prejuicio y mesianismo de una manera interesante y original — celebrando innovaciones contemporáneas como disciplina clerical, el culto a la Virgen de Lourdes y la participación femenina en la vida religiosa cotidiana, pero condenando a la Iglesia romana, a su papa, su jerarquía eclesiástica, su mala administración financiera, su participación política, a la

\footnotetext{
35 The Urologic and Cutaneous Review, 1920, vol. 20: 421.

${ }^{36}$ Muñoz, 1960: 176; Excélsior, 5 de abril de 1920.

${ }^{37}$ Excélsior, 13 de abril de 1922.
} 
Virgen de Guadalupe, las imágenes sobrevestidas, a los curas, mal vestidos y los préstamos de guerra- ${ }^{38}$.

Sin embargo, en forma más inmediata, los paseos teológicos y políticos de Di Gabrielli y su rápida aceptación en Tequisistlán sugieren una lengua común transatlántica de heterodoxia católica nacida del patrimonio mutuo y de los excesos violentos de la década de 1910. Primero, los argumentos de Di Gabrielli eran poderosamente antiautoritarios. En su testimonio y sus discursos reclamó que la iglesia contemporánea estaba "de luto" porque el papa, Benedict XV, había asesinado al papa anterior en alianza con el cardenal Merry del Valle $[s i c]^{39}$. La acusación parece no tener base, a pesar de los exagerados reclamos contra el papa en Europa. En realidad, Benedict XV degradó a Rafael Merry del Val después de la muerte de su patrón, Pius X, en 1914 (Duffy, 2006: 328-333). La acusación muestra una fuerte tensión antiepiscopal en los movimientos populares religiosos, que culpaban a la alta iglesia de los trastornos mundiales (Cohn, 1970). Segundo, la pretensión de Di Gabrielli de ser Cristo y su argumento de que solamente a través de su muerte en creencias penitentes en las regiones más aisladas del mundo católico (como las Filipinas, Nuevo México y Oaxaca), donde la Iglesia tuvo dificultad para erradicar los cultos de flagelación y crucifixión (Trexler, 2003; Carroll, 2002; McAndrew, 2001). Tercero, el deseo de Di Gabrielli de crear una "Iglesia nueva", que llamó la Santa Religión Católica Cardenalicia Mundial, de convocar a obispos a un congreso mundial de todas las naciones "sin distinción de raza ni color" y devolver la deuda mundial "con el dinero de la Iglesia y de los millonarios del mundo" descubre una veta igualitaria común a la de muchos movimientos religiosos de la época (Hobsbawm, 1965: 57-107).

Si las creencias del italiano eran comunes entre los movimientos cristianos radicales del mundo, encontraron resonancia en Tequisistlán, que había mantenido una sinergia excéntrica de creencias católicas y prehispá-

\footnotetext{
${ }^{38}$ ARPU, Testamento de José di Gabrielli.

${ }^{39}$ Probablemente el cardenal Rafael Merry del Val.
}

nicas a pesar de 400 años de evangelización. Tequisistlán era un pueblo indígena en la frontera de la región chontal. Desde la Conquista, la jerarquía episcopal se había quejado de la dificultad del trabajo pastoral entre los chontales. Aunque los dominicos establecieron un convento en Tequisistlán, no pudieron lograr un pacto con los grupos chontales cercanos. Pocos chontales se congregaban en torno al monasterio, y en 1660 los indígenas se levantaron contra los españoles en una alianza con sus vecinos zapotecos (Barabas, 1989: 121-125). La Iglesia tampoco tuvo éxito durante el siglo XIX. Las inquietudes sobre la falta de clérigos, la desobediencia de los indígenas y la persistencia de prácticas prehispánicas salpican el Archivo General de la Nación y el Archivo de la Arquidiócesis de Antequera ${ }^{40}$. La pequeña diócesis de Tehuantepec se estableció en 1891 para concentrar los esfuerzos eclesiásticos, pero no tuvo éxito. Las cartas pastorales de los obispos revelan las persistentes tensiones entre el clero y los fieles. Por una parte, la diócesis no consiguió reunir suficientes curas locales. Varios obispos anunciaron sus planes de establecer un seminario regional en 1900, 1902 y 1905, pero esto no ocurrió ${ }^{41}$. En 1912, el obispo Ignacio Placencia y Moreira se quejó de que todavía no había un "clero genuinamente regional", que faltaban disciplina y jóvenes con una "educación totalmente cristiana" 42 . Por consiguiente, la mayoría de los sacerdotes vino de la capital, de Antequera o de países extranjeros. Durante la Revolución, el cura de Tequisistlán era un italiano, Luis M. Brumi ${ }^{43}$. Además, mientras la diócesis de Huajuapan tuvo un cura por cada 3000 a 4000 habitantes, Tehuantepec tuvo menos de uno por cada 6000 fieles. Por otra parte, las autoridades diocesanas también se resistieron a hacer un compromiso directo con sus feligreses indígenas. Los discursos religiosos eran en español y los curas no hablaban el zapoteco y mucho menos

\footnotetext{
${ }^{40}$ Archivo General de la Nación, Justicia Eclesiástica, vol. 169, fs. 64-71.

${ }^{41}$ Church of the Latter Day Saints, Colección microfilmada (CLDS, CM), Cordilleras de la Parroquia de Magdalena Tequisistlán, 1900-1938.

42 CLDS, CM, Cordilleras de la Parroquia de Magdalena Tequisistlán, 1900-1938, Circular de noviembre de 1912.

${ }^{43}$ Archivo de la Parroquia de Magdalena Tequisistlán, Libro de Bau-
} tismos. 


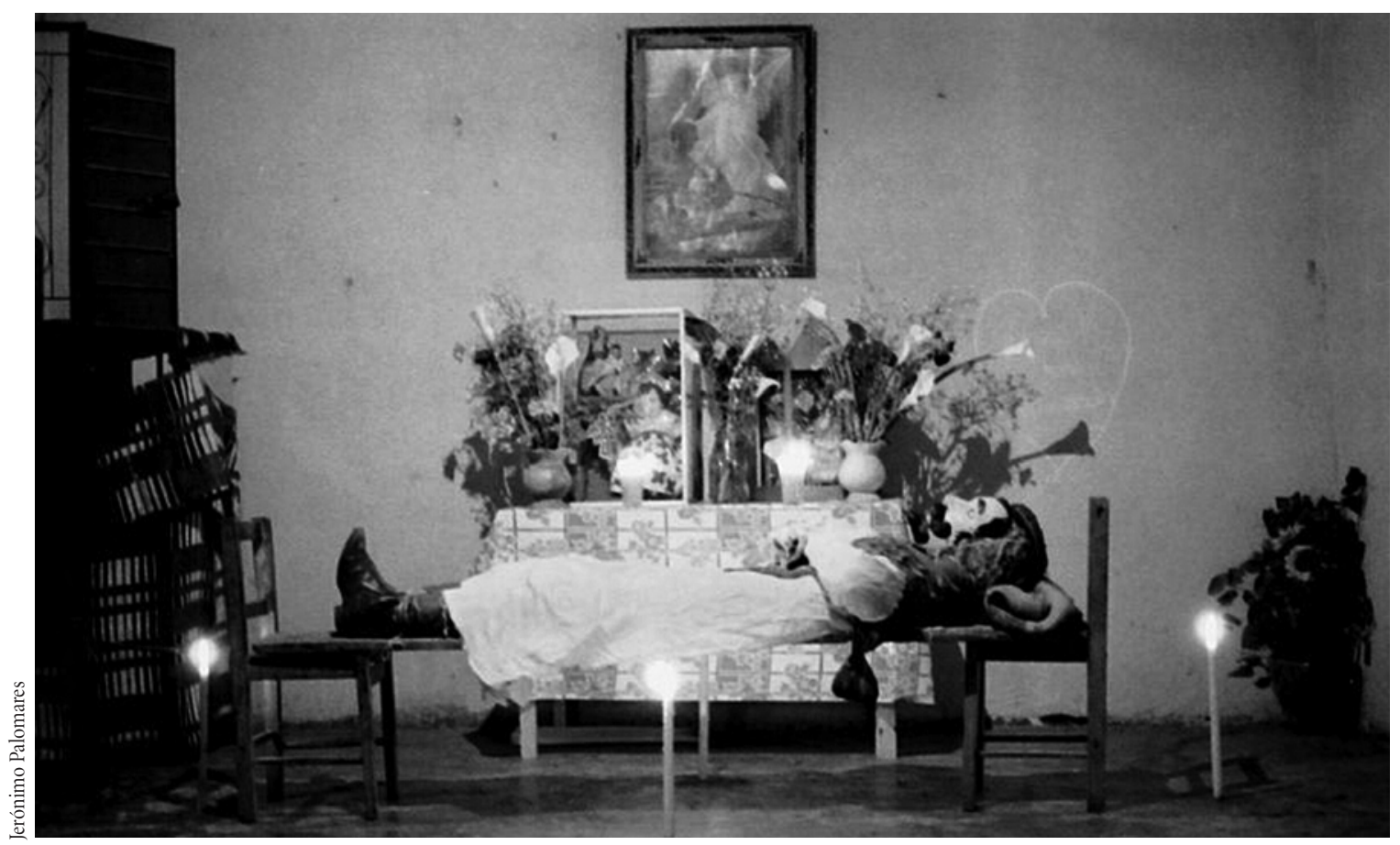

Semana Santa en Venustiano Carranza, Chiapas, 2005.

el chontal ${ }^{44}$. La visita parroquial del obispo, en 1908, deja ver un abismo entre las expectativas clericales y la religiosidad laica. El prelado lamentaba que nadie acudiera a las clases de catecismo y que los pueblos fueran "negligentes, desatentos y hacían poco o nada para cumplir con sus deberes religiosos" 45 .

En Tequisistlán, la Iglesia no pudo establecer un diálogo sostenido con los fieles indígenas. Por consiguiente, los laicos de la comunidad moldearon sus métodos para el renacimiento espiritual de sus creencias prehispánicas y menos ortodoxas. Aunque Di Gabrielli no fue criptopagano, su afirmación de poder curar, su mesianismo y sus profecías apocalípticas y de la inminente renovación embonaron con la teología chontal. Estas "comprensiones a medias" o incomprensiones mutuas casuales fueron

\footnotetext{
${ }^{44}$ CLDS, CM, Cordilleras de la Parroquia de Magdalena Tequisistlán, 1900-1938, Circular 6, 1903.

${ }^{45}$ CLDS, CM, Cordilleras de la Parroquia de Magdalena Tequisistlán, 1900-1938, Visita parroquial, 1908.
}

vitales para el breve movimiento (Burkhart, 1996). Cuando el juez de Tehuantepec preguntó a los cuatro presos de Tequisistlán por qué creyeron que Di Gabrielli era Jesucristo, respondieron que había "curado a los enfermos" y hecho otras "obras de caridad para los enfermos" 46 . A principios del siglo XIX, en los pueblos más aislados no había doctores, por lo que tener algunos conocimientos médicos era muy valorado. Pero los chontales apreciaban a los curanderos u onši más que la mayoría de los grupos indígenas. Según Pedro Carrasco, quien estudió el sistema de creencias de los chontales durante la década de 1940, los onši eran "muy importantes". Igual que los sacerdotes prehispánicos, tenían que hacer un entrenamiento intensivo y largos periodos de ayuno y continencia. Además, los chontales creían que su entrenamiento los imbuía de poderes especiales para contactar el mundo de los espíritus, negociar con ellos el fin de una enfermedad y hasta volverse invisibles (Carrasco,

\footnotetext{
${ }^{46}$ APRU, Documentos judiciales de José di Gabrielli.
} 


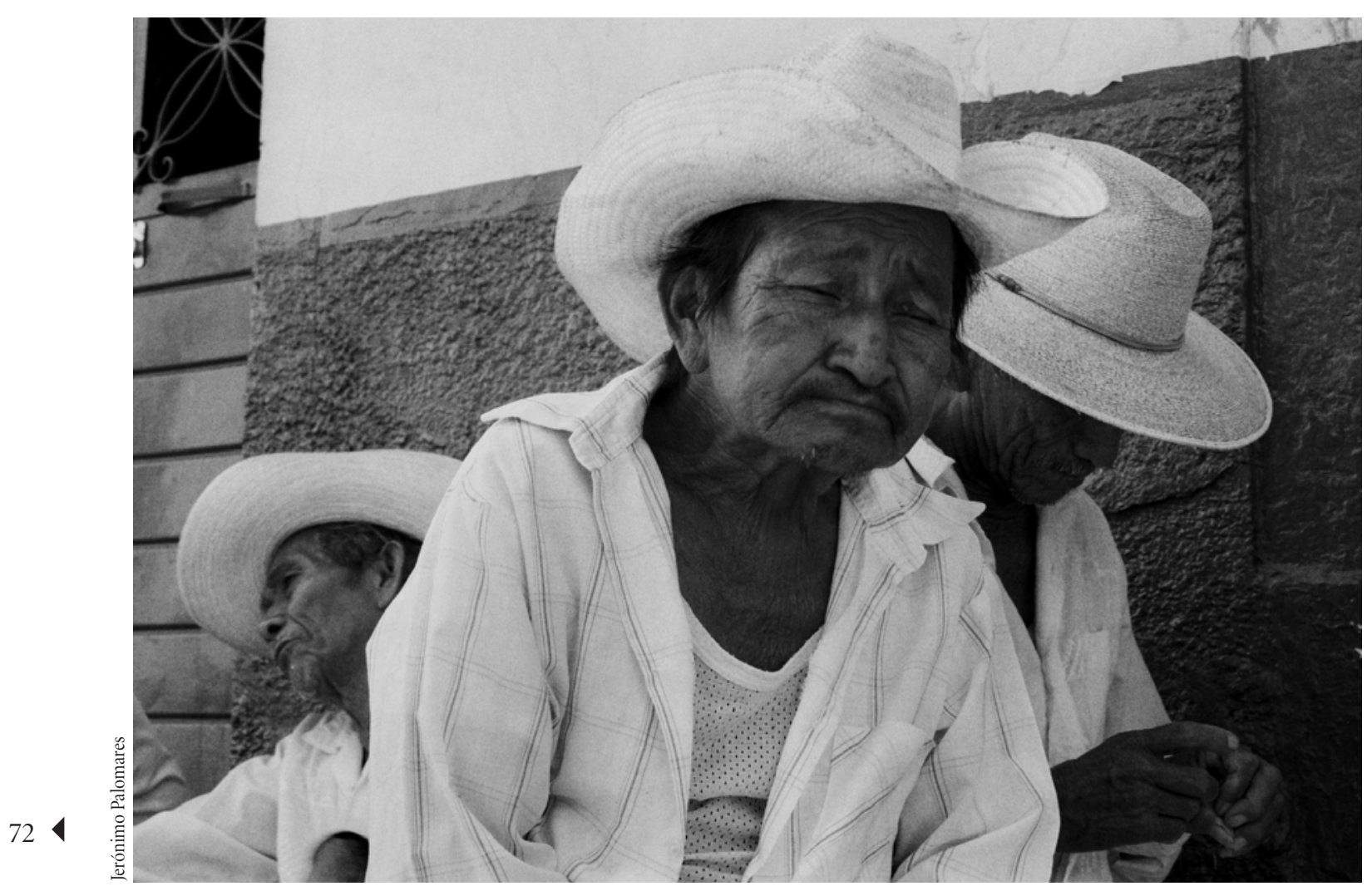

Venustiano Carranza, Chiapas, 2005.

1960: 110). Así, aunque Di Gabrielli probablemente ofrecía ayuda médica para ganar la confianza de los chontales, en realidad, sin saberlo, reforzaba su pretensión de manipular la intercesión divina.

Aunado a lo anterior, la afirmación de Di Gabrielli de ser Cristo también se relacionó con una importante leyenda que proponía que un rey chontal, Fane Kantsini (Tres Colibrí), regresaría y defendería a su pueblo de las fuerzas externas. Según esta poderosa leyenda, Fane Kantsini nació de un huevo y fue cuidado por sus padres ancianos. Antes de ser adulto liberó la región de los reyes malos y gobernó la tierra desde su palacio en el cerro Jilote. Durante su reinado, luchó contra sus vecinos zapotecos. Eventualmente, Fane Kantsini decidió purgar la región del grupo rival, se volvió águila y robó a todos los niños del pueblo zapoteco de Tlacolulita. Cuando los zapotecos atacaron, usó su fuerza sobrehumana para vencerlos. Después, el rey chontal se fue, pero prometió regresar y salvar a los chontales una vez más en caso de peligro (Bartolomé y Barabas, 2006). El mito del poderoso rey que regresaría para defender al pueblo fue común en Mesoamérica y la leyenda conservó su poder milenario entre los mixes y chontales de Oaxaca. En la década de 1930, el líder mixe Luis Rodríguez usó el mito del rey mixe Cong Hoy para reforzar su cacicazgo, encargando canciones al rey, nombrando escuelas y cooperativas en honor al monarca y tratando de usurpar su papel de defensor de los mixes (Smith, 2008). Aunque los chontales llamaron Cristo a José Di Gabrielli, su papel fue más cercano al regreso de un vengador. En consecuencia, Inocente Domínguez dijo que creía que Di Gabrielli "redimiría y salvaría el pueblo", y Pánfilo Patricio que después del sacrificio "el pueblo [...] llevaría el nombre de Tierra Santa”. De nueva cuenta, los chontales reinterpre- 
taron e inscribieron en sus propias creencias las afirmaciones de Di Gabrielli ${ }^{47}$.

En sus discursos en Tequisistlán y en su testimonio, Di Gabrielli aseguraba que su crucifixión causaría el temblor de la tierra y el ensombrecer del cielo, el apocalipsis antes de la redención. Aunque sus afirmaciones estaban enraizadas en la escatología cristiana, hicieron eco de la tradición apocalíptica chontal que sobrevivió a las creencias de otros grupos más aculturados. Al inicio del siglo XX, un ortodoncista japonés, Masanosuke Oguita, anotó una serie de canciones chontales en Tequisistlán. Una de ellas, llamada “Dios quiere acabar el mundo", revela esta persistente mitología. Decía la canción que Dios quería acabar con el mundo pero el canto de los pájaros logró convencerlo de no hacerlo ${ }^{48}$. En la década de 1940, Carrasco describió otro mito chontal que alegaba que Dios guardó todos los rayos en una caja, en una isla en el Pacífico. La caja contenía suficientes rayos para "destruir el mundo" (Smith, 2008). Estos mitos indígenas de destrucción inmanente apoyaban las heterodoxas creencias cristianas de Di Gabrielli.

Si la crucifixión de Di Gabrielli revela el deseo de intercesión divina, la persistencia de creencias prehispánicas y la importancia de la contingencia histórica también indican dónde y por qué el Estado mexicano tenía una mejor estrategia que la Iglesia católica. Distinto de Tequixtepec, Tequisistlán se volvió un municipio modelo posrevolucionario y abrazó la educación secular y el anticlericalismo del Estado. Los habitantes recuerdan la crucifixión con vergüenza. Muchos creen que el doctor italiano y el cura italiano tramaron la crucifixión como parte de una apuesta para probar la credulidad y la estupidez de sus ancestros $^{49}$. Según Ángel Bustillo Bernal, Di Gabrielli ganaría 50000 dólares en los Estados Unidos si podía convencer a los mexicanos de que era el anticristo (Bustillo Bernal, 1968: 135). La afirmación no tiene fundamentos. Cuando Di Gabrielli murió en Sicilia, en 1922, mantenía que era el mesías ${ }^{50}$. Sin embargo, la creencia chontal reve-

\footnotetext{
${ }^{47}$ APRU, Documentos judiciales de José di Gabrielli.

${ }^{48}$ Masanosuke Oguita, Canción de Chontal (s. e., s. f.).

${ }^{49}$ Entrevista con Melquías Domínguez, enero de 2008.

${ }^{50}$ Excélsior, 13 de abril de 1922.
}

la la desconfianza hacia los curas locales y extranjeros, y que la disposición de los indígenas concordaba con el nacionalismo, el paternalismo y el anticlericalismo del Estado posrevolucionario. Por consiguiente, cuando los maestros rurales llegaron en la década de 1920, fueron bienvenidos, y cuando el gobierno mandó cerrar las iglesias en 1926, los vecinos no se quejaron ${ }^{51}$. Más tarde, cuando los maestros socialistas introdujeron obras de teatro didácticas anticlericales, atacaron a las autoridades diocesanas y prohibieron las ceremonias religiosas, la gente de Tequisistlán apoyó estas medidas ${ }^{52}$.

\section{CONCLUSIÓN}

En general, las historias del Señor del Perdón y de los matacristos demuestran cómo ciertos pueblos no abrazaron la Revolución pero buscaron aplacar la ira de Dios a través de la manipulación de la iconografía y las prácticas religiosas. Estos dos movimientos se inscriben en lo que Antony Wallace llamó "movimientos de revitalización" o "esfuerzos deliberados, organizados y conscientes" de miembros de una sociedad sometida a estrés "para construir una cultura más satisfactoria” (Wallace, 1956: 265). Según Matthew Butler, la Revolución fue un "periodo de fermento religioso genuino y agitación social”. Además, "la religión y la Revolución estaban vinculadas en una dialéctica en la que la radicalización de la sociedad [y tal vez la destrucción y la violencia desatada] era acompañada de respuestas innovadoras; a menudo, improvisadas en la esfera religiosa" (Butler, 2006).

No obstante, estos dos movimientos fueron diferentes. La crucifixión de Tequisistlán fue milenaria y mesiánica, expectante del apocalipsis inminente, y revela una obsesión por el salvador divino hecho carne. Según historiadores como Serge Gruzinski, Enrique Florescano, Jacques LaFaye y Kevin Gosner, estos movimientos poco ortodoxos

\footnotetext{
${ }^{51}$ Archivo del Poder Ejecutivo del Estado de Oaxaca, Religión. Entre las múltiples peticiones de casi todas las regiones de Oaxaca no hay una del pueblo de Tequisistlán.

${ }^{52}$ Archivo Histórico de la Secretaría de Educación Pública, Caja 120, exp. 3 .
} 
prosperaron durante la época colonial, culminando, según Eric van Young, en el movimiento de Independencia, que trasladó un sentido centrado en la localidad y "truncado" de expectación milenaria a la figura de Fernando VII (Van Young, 2001: 458-460). Según Paul Vanderwood, el "fuerte contenido milenario" en la religión popular mexicana continuó hasta la época revolucionaria, estimulando nuevos cultos y movimientos de inconformes desde Tomóchic hasta Tijuana. Tal vez Vanderwood tenga razón. Hace una lista de mesías, visionarios, curanderos y sectas poco ortodoxas ubicados en los desiertos del norte de México (Vanderwood, 2003). Edward Wright-Rios, Francie Chassen-López y Massimo De Giuseppe dan otros ejemplos de las innovaciones drásticas (Wright-Rios, 2009; Chassen-López, 1998; De Giuseppe, 2006). Incluso en el centro del catolicismo clerical, en Puebla, Querétaro, Jalisco y Michoacán, hubo apariciones y visiones apocalípticas, mesías locos y Moisés modernos (Butler, 2006; 10-12; Meyer, 1973-1975, vol. I: 349-350). Sugiero que estos movimientos religiosos no autorizados, por el hecho de revelar y cimentar la porcionaron un amplio espacio en el cual el anticlericalismo revolucionario podía florecer. Durante las décadas de 1920 y 1930, maestros, agraristas y burócratas llenaron esos espacios, establecieron las instituciones del Estado en contraposición a las de la Iglesia y reforzaron el anticlericalismo popular, frecuentemente por "la transferencia de la sacralidad" de cultos fracasados a iconos revolucionarios.

Pero el "gran abismo" entre la religión popular y la élite no debería sobreestimarse. Van Young sugiere que el proceso de secularización nacido de la urbanización, de la expansión de ideas liberales, de los modernos medios de comunicación, de la educación laica y el nacionalismo gradualmente disminuyó el milenarismo popular durante el siglo XIX (Van Young, 2000: 520-522). Pero el levantamiento del culto del Señor del Perdón en Tequixtepec manifiesta que, de hecho, la secularización no eliminó estas creencias. Más bien, las autoridades eclesiásticas las "autorizaron" al percibir que para sobrevivir y prosperar tenían que abrazar estas convicciones con entusiasmo pero encauzándolas hacia prácticas católicas más aceptables. A lo largo del “eje católico geopolítico" y de regiones más amplias de la evangelización porfirista, los curas aprovecharon el sentido de expectación providencial intensificado y lo utilizaron para reforzar las relaciones entre el clérigo y el sector laico, creando nuevos santuarios, imágenes y peregrinaciones, y reforzando los tradicionales. En la diócesis de Huajuapan de León, el obispo y los curas visitaban las cuevas que contenían imágenes de la Virgen de Guadalupe hechas de piedra, adoradas anteriormente en secreto, y pedían la redención ${ }^{53}$. Renovaron la devoción a la Virgen de las Nieves de Ixpantepec y vieron con beneplácito la introducción de iconos y devociones particulares en las parroquias ${ }^{54}$. En Juxtlahuaca, el cura alentó a los vecinos indígenas a llevar la imagen de la iglesia mestiza del centro a la iglesia indígena de su barrio, a establecer una nueva cofradía y a hacer fiestas más eficaces para adorar la imagen (Beristáin Romero, 2001: 138-139). Así como las presiones revolucionarias abrieron la puerta al anticlericalismo en algunos lugares, también la cerraron con fuerza en otros para introducir una lengua compartida de devoción religiosa. Estas regiones de reciente "transculturación de milagros" se volvieron bastiones contra el anticlericalismo de las décadas siguientes. Aquí, curas más flexibles infundieron un nuevo vigor en la organización parroquial, rechazaron el agrarismo estatal, la educación socialista y el kulturkampf posrevolucionario, despojaron al PRI local de sus extremistas jacobinos o abrazaron el sinarquismo o el PAN (Smith, 2007).

\section{Bibliografía}

Alcalá Alvarado, Alfonso, 1984, "La Iglesia camina por nuevos senderos (1873-1900)", en Enrique Dussel (coord.), Historia general de la Iglesia en América Latina, México, vol. 5, Sígueme, Salamanca, pp. 264-288.

Al-Shimas, Kamar, 1922, The Mexican Southland, Benton Review, Fowler.

${ }^{53}$ Historia de Tonalá, Oaxaca coleccionada por el Sr. Pbro. D. Avelino de la T. Mora López para Conmemorar el III Centenario del Hallazgo de La Santa Cruz. En la Gruta del Rio de Santa Maria Tindu, Oax. (Santo Domingo Tonalá: s.e., 1957).

${ }^{54}$ Archivo de la Parroquia de Chila, Libros de Gobierno, 3 de mayo de 1911. 
Barabas, Alicia, 1989, Utopías indias: movimientos sociorreligiosos en México, Grijalbo, México.

Bartolomé, Miguel y Alicia Barabas, 2006, "Narrativa chontal: la leyenda del rey Fane Kantsini”, en Andrés Oseguera (coord.), Historia y etnografía entre los chontales de Oaxaca, Instituto Nacional de Antropología e Historia, México, pp. 175-182.

Beristáin Romero, Cándido, 2001, Yosocuiya, Juxtlahuaca a través de su historia, Cándido Beristáin Romero ed., Santiago Juxtlahuaca.

Blok, Anton, 1972, “The Peasant and Brigand: Social Banditry Reconsidered", Comparative Studies in Society and History, núm. 14, pp. 494-503.

Brading, D. A., 2001, Mexican Phoenix, Our Lady of Guadalupe: Image and Tradition Across Five Centuries, Cambridge University Press, Cambridge.

Brunk, Samuel, 1996, "The Sad Situation of Civilians and Soldiers: The Banditry of Zapatismo in the Mexican Revolution", The American Historical Review, vol. 101, núm. 2, pp. 331-353.

Bustillo Bernal, Ángel, 1968, La Revolución Mexicana en el Itsmo [sic] de Tehuantepec, Editora Mexicana de Periódicos y Libros y Revistas, S. A., México.

Butler, Matthew, 2006, "Introduction, A Revolution in Spirit? Mexico 1910-1940”, en Matthew Butler (ed.), Faith and Impiety in Revolutionary Mexico, Palgrave, Londres, pp. 1-20.

Cantú Córro, José, s. f., In Memoriam Ilmo. y Rvdmo. Sr. Dr. D. Rafael Amador y Hernández, Primer Obispo de Huajuapan de León, Huajuapan de León.

Carrasco, Pedro, 1960, "Pagan Rituals and Beliefs among the Chontal Indians of Oaxaca", Anthropological Records, vol. 20, núm. 3, pp. 87-118.

Carroll, Michael P., 2002, The Penitente Brotherhood: Patriarchy and Hispano-Catholicism in New Mexico, Johns Hopkins University Press, Baltimore.

Chassen-López, Francie, 1998, "Maderismo or Mixtec Empire? Class and Ethnicity in the Mexican Revolution, Costa Chica of Oaxaca, 1911", The Americas, vol. 55, núm. 1, pp. 91127

_ 2005, From Liberal to Revolutionary Oaxaca: The View from the South, México 1867-1911, University Park, University of Pennsylvania, Pennsylvania.

Cohn, Norman, 1970 The Pursuit of the Millennium: Revolutionary Millenarians and Mystical Anarchists of the Middle Ages, Oxford University Press, Oxford.

Dirección General de Estadísticas, 1906, Censo General de la República Mexicana/Estado de Oaxaca, Secretaría de Fomento, Colonización e Industria, México.

De Giuseppe, Massimo, 2006, “'El Indio Gabriel': New Religious Perspectives among the Indigenous in Garrido Cana- bal's Tabasco (1927-1930)", en Matthew Butler (ed.), Faith and Impiety in Revolutionary Mexico, Palgrave, Londres, pp. 225-242.

Duffy, Eamon, 2006, Saints and Sinners: A History of the Popes, Yale University Press, Yale.

González y González, Luis, 1985, "La Revolución Mexicana desde el punto de vista de los revolucionados'”, Historias, núms. 8-9, pp. 5-14

Guerra, Francisco Xavier, 1985, Le Mexique del'Ancien Régimeà la Révolution, L'Harmattan-Publications de la Sorbonne, París.

Gutiérrez Casillas, José, 1974, Historia de la Iglesia en México, Porrúa, México.

Hernández Madrid, Miguel J., 1994, "Después de los arreglos. ¿Complicidad o secularización de las conciencias? La Pastoral Cívica del obispo Manuel Fulcheri y Pietra Santa en Zamora, Michoacán, después de 1929”, Relaciones, vol. 16, núm. 60, pp. 141-166

Hobsbawm, Eric, 1959, Bandits, Liedenfeld and Nicholson, Londres.

, 1965, Primitive Rebels: Studies in Archaic Forms of Social Movement in the 19th and 20th Centuries, W. W. Norton \& Company, Londres.

Knight, Alan, 1986, The Mexican Revolution, 2 vols., Cambridge University Press, Cambridge.

Louise M. Burkhart, 1996, Holy Wednesday: A Nahua Drama from Early Colonial Mexico, University of Pennsylvania Press, Philadelphia.

McAndrew, John P., 2001, People of Power: a Philippine WorldView of Spirit Encounters, Ateneo de Manila University Press, Manila.

Meyer, Jean, 1973-1975, La Cristiada, 3 vols., Siglo XXI Editores, México.

Monaghan, John, 1995, The Covenants with Earth and Rain, Exchange, Sacrifice, and Revelation in Mixtec Sociality, University of Oklahoma Press, Norman.

__, 2002, "El pan y las comunidades de la Mixteca Baja", ponencia, Reunión de la American Anthropological Society, Oaxaca de Juárez.

Muñoz, Ignacio, 1960, Verdad y mito de la Revolución Mexicana, 4 vols., Ediciones Populares, México.

Ochoa Hernández, Jesús, 1987, "El Crucificado de Tequisistlán”, Excélsior, 16 abril, pp. 12-13.

O'Dogherty, Laura, 1998, "El ascenso de una jerarquía eclesial intransigente, 1890-1914”, en Manuel Ramos Medina (ed.), Historia de la Iglesia en el siglo XIX, Condumex, México, pp. 179-198.

Reyes Aguilar, Saúl, 1972, Mi madre y yo: sucesos históricos en la Mixteca, Ediciones Botas, México.

Ramírez Díaz, Leonardo, 2005, Magdalena Tequisistlán: la llave del istmo: ensayo histórico social, s. e., Tequisistlán. 
Sánchez R., Martín, 1992, “Los católicos, un grupo de poder en la política michoacana (1910-1924)”, Relaciones, vol. 13, núm. 51, pp. 195-222.

Singer, Leticia, 1998, "El Cristo que crucificaron en Oaxaca", Siempre, 31 diciembre, pp. 12-15.

Smith, Benjamin T., 2007, “The Priest's Party': Local Catholicism and Panismo in Huajuapan de León”, en Matthew Butler, Faith and Impiety in Revolutionary Mexico, Palgrave, Londres.

_ 2008 , "Inventing Tradition at Gunpoint: Culture, Caciquismo and State Formation in the Region Mixe, Oaxaca (1930-1959)", Bulletin of Latin American Research, vol. 27, núm. 3, pp. 215-234.

_ 2009, Pistoleros and Popular Movements: The Politics of State Formation in Postrevolutionary Oaxaca, University of Nebraska Press, Lincoln.

Taylor, William, 1996, Magistrates of the Sacred: Priests and Parishioners in Eighteenth-Century Mexico, Stanford University Press, Stanford.

Trexler, Richard C., 2003, Reliving Golgotha: The Passion Play of Iztapalapa, Harvard University Press, Cambridge.

Valverde Téllez, Emeterio, 1949, Bio-bibliografía eclesiástica mexicana (1821-1943), Jus, México.

Vanderwood, Paul, 2003, “The Millennium and Mexican Independence", en Christon Archer, The Birth of Modern Mexi165-186.

Van Young, Eric, 2001, The Other Rebellion, Stanford University Press, Stanford.

Wallace, Antony F. C., 1956, "Revitalization Movements", American Anthropologist, vol. 58, núm. 2, pp. 264-281. 